\title{
POR QUÉ NO ESTÁBAMOS PREPARADOS PARA EL CORONAVIRUS*
}

David Quammen ${ }^{\mathrm{a}}$

* DOI: https://doi.org/10.18601/01245996.v23n44.03. Recepción: 15-052020, aceptación: 27-11-2020. Sugerencia de citación: Quammen, D. (2021). Por qué no estábamos preparados. Revista de Economía Institucional, 23(44), 53-70.

a Escritor y divulgador científico. Autor de Contagio. La evolución de las pandemias. Barcelona: Debate, 2020. 


\section{Por qué no estábamos preparados para el coronavirus}

Resumen Este artículo de David Quammen, autor del recomendable libro Contagio. La evolución de las pandemias, hace una breve síntesis de las últimas investigaciones sobre las enfermedades epizoóticas, causadas por virus que saltan de otras especies animales a la especie humana, y es una especie de adenda al epílogo de la versión en castellano, titulado "Fuimos nosotros quienes creamos la epidemia del coronavirus". En este artículo Quammen argumenta que a Estados Unidos le ha ido peor que a otros países, no porque haya carecido de información o de financiación, sino porque no aprendió las lecciones de los últimos brotes.

Palabras clave: coronavirus COVID-19; JEL: H50

\section{Why weren't we ready for the coronavirus?}

Abstract This paper by David Quammen, author of the recommended book Spillover. Animal infections and the next human pandemic, makes a brief synthesis of the latest research on epizootic diseases, caused by viruses that jump from other animal species to the human species, and is a sort of addendum to the epilogue of the Spanish version, entitled "We were the ones who created the coronavirus epidemic". In this paper Quammen argues that U.S. has fared worse than other countries not because it lacked information or funding but because it failed to learn the lessons of the last outbreaks.

Keywords: coronavirus COVID-19; JEL: H50

\section{Por que não estávamos prontos para o coronavírus?}

Resumo Este artigo é de David Quammen, autor do livro recomendado Spillover. Infecções animais e a próxima pandemia humana, faz uma breve síntese das últimas pesquisas sobre doenças epizoóticas, causadas por vírus que saltam de outras espécies animais para a espécie humana, e é uma espécie de adendo ao epílogo da versão espanhola, intitulada "Fomos nós que criamos a epidemia do coronavírus". Neste artigo, Quammen argumenta que se saiu pior do que outros países, não por falta de informação ou financiamento, mas porque não aprendeu as lições do último surtos.

Palavras-chave: coronavírus COVID-19; H50 
- $\mathrm{n}$ 2006, la idea de que un virus desconocido podría pasar de un Canimal salvaje a la especie humana, adquiriendo la capacidad de propagarse de humano a humano y causando una pandemia global, parecía una posibilidad remota para la mayoría de la gente. Una amenaza convincente de ciencia ficción, apenas más creíble que Alien: Resurrección. Pero Ali S. Khan, del Centro Nacional de Enfermedades Zoonóticas, Transmitidas por Vectores y Entéricas (NCZVED), estaba encargado de infiltrarse en esa pesadilla a la luz del día.

La sede del NCZVED, que según Khan se pronuncia "en-si-zved" y es parte de los Centros para el Control y la Prevención de Enfermedades (CDC), estaba ubicada en un discreto edificio de ladrillo gris, bien protegido por verjas con barrotes y puertas con cerrojos, en el complejo del CDC en Clifton Road, a unos diez kilómetros al noreste del centro de Atlanta. Ese año, durante una visita de dos días pasé por los corredores del NCZVED entrevistando científicos que sabían todo acerca de los virus del Ébola (sí, hay más de uno) y de su letal primo, el virus de Marburgo; del virus del Nilo Occidental en el Bronx y del virus Sin Nombre en Arizona; del virus espumoso del simio en Bali, transmitido por monos de los templos que saltan sobre los turistas, y de la viruela del mono, que llegó a Illinois en ratas gigantes de Gambia vendidas como mascotas; del virus Junín en Argentina y del Machupo en Bolivia; del virus de Lassa en Âfrica Occidental, del Nipah en Malasia, del Hendra en Australia y de los virus de la rabia en todas partes. Todos estos virus son zoonóticos, lo que significa que pueden pasar de animales a humanos. La mayoría de ellos, una vez dentro del cuerpo humano, causan estragos. Algunos se transmiten fácilmente entre humanos, causando brotes locales que pueden matar a cientos de personas. Son nuevos para la ciencia y para el sistema inmunológico humano; surgen de manera impredecible y son difíciles de tratar; y pueden ser especialmente peligrosos, como indica el nombre de la sección del NCZVED que los estudiaba: "Patógenos Especiales". Por estas razones, algunos científicos y expertos en salud pública, incluido Ali Khan, consideran que los virus son un desafío irresistible. "Por ello te mantienen siempre en alerta”, me dijo. El segundo día de mi visita, en un descanso de nuestras fascinantes pero horripilantes sesiones informativas, Khan me llevó a comer sushi.

Médico por formación y epidemiólogo por profesión, Khan es un hombre de humor sincero e irreverente. Llevaba un suéter militar con charreteras; en esa época era también funcionario del Servicio de Salud Pública de Estados Unidos, que está organizado por rangos, 
como los de la Marina. "Escuchaste todo lo que dijo nuestra gente", me dijo. “¿cuál de estas enfermedades es tu favorita?"

¿Mi favorita? El ébola es muy interesante, le dije.

"Aaah", dijo Khan desdeñosamente. "Me gusta el ébola tanto como cualquier otra". Hizo una labor epidemiológica fundamental durante el brote de ébola de 1995 en Kikwit, en lo que entonces era Zaire, organizando medidas de control, investigando los métodos de transmisión, rastreando el brote hasta el Paciente Cero, arriesgando vida para ayudar a detener esa ola abrumadora de infelicidad y muerte. "Pero en lo que a mí respecta es el SARS".

¿E1 SARS? Yo solo sabía que era una enfermedad viral grave que apareció en el sur de China en 2003 y mató gente en Toronto, Singapur y otras ciudades. $\mathrm{El}$ acrónimo significa "síndrome respiratorio agudo severo". Es una peligrosa enfermedad que puede provocar neumonía mortal. Un poco más de ocho mil personas se infectaron, un $10 \%$ de ellas murió y luego terminó el brote. “¿Por qué el SARS?”, le pregunté.

"Porque era sumamente contagioso y muy letal", me dijo. "Y tuvimos mucha suerte de detenerlo". El SARS fue la bala que pasó silbando al oído de la humanidad. Era nuestro descanso para almorzar, había dejado de tomar notas y fue hace 14 años, así que no puedo jurar que en esa ocasión Khan mencionó la otra cosa más relevante del SARS: que fue causada por un nuevo coronavirus.

Hoy Ali Khan es decano de la Facultad de Salud Pública del Centro Médico de la Universidad de Nebraska en Omaha. No se parece a los nativos de Omaha: nacido y criado en Brooklyn de padres paquistaníes inmigrantes, asistió al Brooklyn College y luego a la escuela de medicina SUNY Downstate (en Brooklyn). "Después cometí la locura de dejar Brooklyn", una locura para su familia, "porque tengo tíos y tías que aún no han salido de Brooklyn para ir a la ciudad”. Su padre, Gulab Deen Khan, era un hombre que se hizo a sí mismo, de tipo épico: de origen campesino, en la adolescencia viajó de Cachemira a Bombay, mintió sobre su edad y consiguió trabajo en un barco: engrasando motores. Sus amigos lo llamaban Dini, en diminutivo, por su baja estatura. Cuando llegó a Estados Unidos, Dini Khan trabajó alimentando el carbón de las calderas para calentar apartamentos en los edificios de Brooklyn hasta que ahorró lo suficiente para comprar su propio edificio. Hizo bastante dinero, lo que parecía una fortuna. Antes de perderlo, en otra especulación, Dini decidió que su hijo pequeño, Ali, debía conocer la cultura, la religión y el idioma de su familia. Entonces lo envió a Pakistán Ali, a una escuela de enseñanza 
media y secundaria. Por un error de apreciación, eligió un internado clásico británico en Lahore, un mejor lugar para aprender a jugar cricket que para aprender urdu o conocer la religión islámica. Ali Khan, que hoy tiene cincuenta y seis años, me contó esta historia, mezclada con risas, cuando lo contacté recientemente por Skype. Su cabello y su barba oscuros tenían tonos grises, pero aún lucía en forma y jovial. Habló de Omaha como un vocero de la Cámara de Comercio: una gran ciudad, segura, con un estilo de vida sobrio, llena de multimillonarios - como Warren Buffett- que viven en sus antiguas casas familiares, conducen sus pequeños Buicks y giran millones de dólares en cheques para la comunidad.

"Me encanta ser decano", dijo. "Es muy divertido". Se trasladó a Omaha en 2014, luego de dejar el cargo de Director de la Oficina de Preparación y Respuesta de Salud Pública de los CDC, en el que debía supervisar la Reserva Nacional Estratégica de suministros médicos de emergencia y a ochocientos empleados, ayudar a elaborar una estrategia nacional de biodefensa contra amenazas de pandemia, y hacer muchas cosas más. "Al final de mi carrera en los CDC, manejaba un presupuesto de mil millones y medio de dólares, de modo que administraba personas y dinero". Había viajado por el mundo para organizar la respuesta a diversos brotes, desde Wyoming hasta Bangladesh. En una misión al sur de Chile, para investigar un brote de hantavirus, fue a aldeas remotas, a veces a caballo, con el fin de atrapar roedores para determinar qué especies portaban el virus. "Muy pronto supimos que había muchos roedores", dijo. Después de su trabajo sobre la fiebre del Valle del Rift en Arabia Saudita, en 2001, el Ministro de Salud de Arabia Saudita le dio una réplica en acrílico de un sable para decapitar en señal de gratitud. Durante un brote de viruela símica en Zaire central, él y su equipo se enteraron de que se acercaban dos grupos de combatientes en la guerra civil: la guerrilla de Laurent Kabila y las fuerzas del presidente Mobutu. "Es probable que se lleven sus vehículos y su equipo", les advirtió un contacto de la embajada estadounidense por teléfono satelital. "Pero probablemente no te maten”. El grupo de Khan empacó rápidamente y se embarcó en un pequeño avión, que se elevó directamente hacia una tormenta violenta. "E1 tipo a mi izquierda estaba rezando", relató Khan en The Next Pandemic, un libro lleno de coloridas aventuras de campo y serias advertencias, publicado en 2016. "Miré al médico francés que estaba sentado a mi lado y vi que escribía una nota de despedida a la familia. Eso me hizo pensar". Pensó que esta es una profesión arriesgada, y el trabajo debe valer la vida de una persona. Durante más de veinte 
años en los CDC así había sido. En 1995 estuvo en Kikwit, Zaire, por el ébola. Al año siguiente fue al Sultanato de Omán para ayudar con la fiebre hemorrágica de Crimea-Congo. En 2001, en Uganda, de nuevo por el Ébola. En Singapur, por el SARS, en 2003. Chad aún luchaba por erradicar la poliomielitis en 2008, y Khan fue allí.

Pero hacia el final de su estadía en los CDC, como funcionario de alto nivel, era responsable de la organización, no de la investigación. La ciencia era una pequeña parte de la labor. "Hoy casi toda es ciencia”, me dijo. Virología, epidemiología, ecología y otros aspectos del estudio de las enfermedades constituyen la esencia de su misión: "educar a la siguiente generación de profesionales de la salud pública".

La decoración ecléctica de su oficina actual incluye micrografías electrónicas de varios patógenos, colgadas en la pared como retratos en un galería de villanos, dos esculturas de mosquitos tan grandes como cuervos, un reloj Star Wars, un robot de juguete Big Hero 6, postales enviadas por niños de todo el mundo, recuerdos y regalos de sus viajes: un incensario congoleño, el sable de decapitación saudí y una pizarra en la que registra lo que él llama "mi métrica". Su preciosa métrica: medidas de avance hacia las metas académicas de su facultad, objetivos científicos, metas filantrópicas para apoyar el trabajo. "Me baso en la evidencia y me guío por la evidencia”, me dijo.

Le pregunté a Khan sobre la COVID-19. ¿Qué salió tan desastrosamente mal? ¿Qué pasó con la preparación para la salud pública que supervisó en los CDC? ¿Por qué la mayoría de los países, y en especial Estados Unidos, no estaban preparados? ¿Por falta de información científica o por falta de dinero?

"Por falta de imaginación", me respondió.

Hubo advertencias. Una de ellas era la enfermedad favorita de Khan, el SARS. A finales de 2002, una "neumonía atípica" de origen desconocido comenzó a extenderse en el sur de China, en la ciudad de Cantón y sus alrededores, una de las mayores aglomeraciones urbanas del planeta. En enero de 2003, el virus llegó a un hospital de Cantón, en el cuerpo de un robusto comerciante de mariscos que sufría una crisis respiratoria. En ese hospital, y luego en una instalación para enfermedades respiratorias a la que fue trasladado, el hombre tosió, jadeó, vomitó y escupió durante la intubación, e infectó a decenas de trabajadores de la salud. Entre el personal médico de Cantón se llegó a conocer como el Rey Veneno. En retrospectiva, los estudiosos de las enfermedades le aplican una etiqueta diferente, lo llaman superdifusor. 
Uno de los médicos infectados, un nefrólogo del hospital, tuvo síntomas similares a los de la gripe, pero luego se sintió mejor e hizo un viaje en autobús de tres horas para ir a la boda del sobrino en Hong Kong. Durante su estadía en la habitación 911 del Hotel Metropole, se volvió a sentir enfermo y propagó la enfermedad a lo largo del corredor del noveno piso. En los días siguientes, otros huéspedes del noveno piso volaron de regreso a Singapur y Toronto, portando la enfermedad. Varias semanas después, la Organización Mundial de la Salud lo llamó SARS (el Metropole, que se hizo famoso, luego cambió de nombre). Para el 15 de marzo, la OMS reportó ciento cincuenta nuevos casos de SARS en todo el mundo.

Surgieron dos misterios, uno urgente y otro inquietante: ¿cuál era la causa, un virus nuevo, y de ser así, de qué tipo? ¿Y de qué tipo de animal provenía? $\mathrm{El}$ primer misterio pronto fue resuelto por un equipo dirigido por Malik Peiris, un médico de Sri Lanka que obtuvo un título de microbiología en Oxford antes de ir a la Universidad de Hong Kong. Peiris se especializó en la influenza, y sospechaba que el $\mathrm{H} 5 \mathrm{~N} 1$, un virus de la gripe problemático molesto en aves y a menudo letal en humanos, pero que no se contagia de persona a persona, puede haber evolucionado a una forma transmisible entre humanos. Su equipo logró aislar un nuevo virus de dos pacientes. Era un coronavirus, no un virus de la gripe, es decir, era de una familia de virus diferente, con distintos rasgos característicos. Pero la mera presencia de este nuevo virus en dos pacientes con SARS no significaba que fuera la causa de la enfermedad. Después, el equipo de Peiris demostró con pruebas de anticuerpos que podía ser el agente del SARS, y el trabajo posterior lo confirmó. Aunque en la tradición anterior se tendía a nombrar los nuevos virus por su origen geográfico -el Ébola era un río; Marburgo, una ciudad alemana; Nipah, un pueblo de Malasia; Hendra, un suburbio australiano- prevaleció una mayor sensibilidad a la estigmatización. El patógeno se conoció como SARS-CoV. Recientemente, su nombre fue cambiado a SARS-CoV-1, y así el agente de la COVID-19 no se llama virus de Wuhan, sino SARS-CoV-2.

E1 SARS llegó a Toronto el 23 de febrero de 2003, portado por una mujer de setenta y ocho años que, con su esposo, pasó varias noches en el noveno piso del Hotel Metropole en un viaje de dos semanas a Hong Kong. La mujer enfermó y murió en su casa el 5 de marzo, acompañada por familiares, incluido uno de sus hijos, que pronto mostró síntomas. Después de una semana de dificultades para respirar, fue a la sala de emergencias y allí, sin aislarlo, le dieron un medicamento a través de un nebulizador, que vaporiza una solución 
líquida y la introduce en la garganta del paciente. "Ayuda a abrir las vías respiratorias”, me dijo Khan, una herramienta útil y segura para prevenir un ataque de asma, por ejemplo. Pero imprudente en caso de un virus sumamente contagioso. "Porque cuando inhalas, tomas todo el virus en tus pulmones y lo exhalas en el aire, en la sala de emergencias donde te están tratando". Otros dos pacientes de la sala de emergencias se infectaron, y uno de ellos pronto fue a una unidad de cuidados coronarios por un ataque cardíaco. Allí infectó a ocho enfermeras, un médico, otros tres pacientes, dos empleados, a su esposa y a dos técnicos. Se podría llamar un súper difusor. Una visita a la sala de emergencias produjo ciento veintiocho casos entre personas relacionadas con el hospital. Diecisiete de ellas murieron.

En Singapur, el primer caso de SARS fue el de una mujer joven que también se hospedó en el Metropole, y que el 1 de marzo buscó ayuda, por fiebre, tos y neumonía, en el Hospital Tan Tock Seng, una de las más grandes instalaciones de Singapur. Tuvo visitas y, cuando algunas de ellas volvieron como pacientes, los médicos sospecharon que era algo contagioso. Luego, en un día, enfermaron cuatro enfermeras del pabellón donde estaba hospitalizada la joven, una anomalía que advirtió Brenda Ang, una médica que estaba a cargo del control de infecciones en el hospital. "Ese fue un momento decisivo para mí", me dijo Ang, una mujer pequeña y franca, cuando la entrevisté en el hospital. "Todo se estaba acelerando". Era el martes 12 de marzo de 2003, el día en que la OMS emitió una alerta mundial sobre esta "neumonía atípica".

Casi al mismo tiempo, Ali Khan llegó a Singapur como consultor de la OMS (apoyado por los CDC) para ayudar a organizar la investigación y la respuesta. Se reunía diariamente con Suok-Kai Chew, el epidemiólogo jefe del Ministerio de Salud, y junto con otros elaboraron estrategias y tácticas, logrando la colaboración del gobierno mediante un grupo de trabajo sobre el SARS. La estrategia de salud pública fue el aislamiento y la cuarentena. "Antes de ese brote, la cuarentena y el aislamiento no se solían usar para tratar brotes de enfermedades infecciosas", me dijo Khan, al menos no en el pasado reciente. Durante las plagas medievales europeas, los desafortunados que se infectaban a veces eran enviados fuera de las murallas de la ciudad, para morir o recuperarse. El puerto marítimo mediterráneo de Ragusa (hoy Dubrovnik) estableció un trentino -una cuarentena de treinta días- para los viajeros que llegaban de zonas afectadas por la peste. En los Estados Unidos de finales del siglo XIX y comienzos del siglo XX, durante los brotes de viruela, las víctimas que tenían los 
síntomas (en especial si eran pobres o de color) podían ser confinadas en campos de cuarentena, rodeados con altas cercas de alambre de púas, o en "lazaretos" dantescos, no tanto para tratarlas sino para seguridad del resto de la población. "Era un concepto pasado de moda", me dijo Khan con ironía. Él, Chew y sus colegas lo revivieron en una versión más humana.

Tan Tock Seng empezó a tratar únicamente a pacientes con SARS, mientras que los demás enfermos se remitían al hospital general de Singapur. Todos los casos sospechosos o probables de SARS se aislaron en Tan Tock Seng, y la definición de "sospechoso o probable" se amplió más allá de las pautas de la OMS para incluir a cualquier persona con fiebre o problemas respiratorios. Todos los trabajadores de la salud usaban equipos de protección personal, incluidas las máscaras N95, y debían controlarse la fiebre u otros síntomas tres veces al día. E1 personal médico también se restringió a la misma instalación, para que no propagara el virus a otros hospitales. Durante los procedimientos riesgosos, como la intubación de un paciente, usaban cascos respiratorios que bombeaban aire purificado.

También se tomaron medidas estrictas para limitar la difusión de la enfermedad en la comunidad. Desde el 27 de marzo se cerraron las escuelas y los cuerpos de quienes morían de SARS se cremaban en un plazo de veinticuatro horas. Los investigadores rastrearon los contactos cercanos de cada nuevo paciente con SARS, también en veinticuatro horas, y luego los sometían a cuarentena obligatoria. "Está bien, quédate en casa. Instalaremos una cámara, y hay un teléfono", dijo Khan, recordando las instrucciones. "Te llamaremos al azar, y debes encender la cámara para que te vean”. Ya había más de ochocientas personas en cuarentena. "Si rompes la cuarentena doméstica llevarás un rastreador electrónico, en un brazalete o en una tobillera”. La cuarentena obligatoria plantea desafíos logísticos, me dijo Khan. "Si encierras a las personas, entonces tienes que cuidarlas". Debes alimentarlas, cuidar su salud, asegurar que tengan vivienda y ropa. “¿Quién las cuida? ¿Quién paga por ellas? Si el gobierno es el que impone el autoaislamiento, él tiene que hacerlo.

Para el 24 de abril habían muerto veintidós personas; en ese momento se endurecieron las sanciones para quienes rompieran la cuarentena: mayores multas, la posibilidad de ir a prisión. A los taxistas se les medía diariamente la temperatura. También se revisaba a los pasajeros que llegaban y salían del aeropuerto de Changi, así como a quienes viajaban en autobuses y en automóviles privados. E1 20 de mayo se multó a once personas por escupir en público, cobrando 300 
dólares a cada una. Esas medidas funcionaron. E1 13 de julio de 2003 salió de Tock Seng, el último paciente con SARS y todo terminó. Hay quienes dicen, con ligereza, que el SARS "se consumió" después de haber matado solo a 774 personas en todo el mundo. No se consumió, como me dijo Ali Khan, fue detenido.

“¿Qué es lo que más te preocupa ahora?”, le pregunté seis años después a Brenda Ang en Tan Tock Seng.

Ella sonrió con frustración. La "autocomplacencia”, me dijo. "Y la apatía". Las medidas mundanas pero esenciales para el control de infecciones (el asiduo lavado de manos y la limpieza de las manijas de las puertas con alcohol) se pueden olvidar después de una crisis. "La gente se vuelve complaciente. Cree que no hay más virus alrededor”. ¿Y las lecciones de mayor alcance, más allá del lugar del brote, más allá de Singapur? "No tiene sentido proteger tu mero territorio", me dijo. "Las enfermedades infecciosas están globalizadas".

Más tarde, Ali Khan me dijo lo mismo: "Una enfermedad infecciosa en un lugar se propaga por doquier".

En 2015 llegó a Corea del Sur un coronavirus diferente, en el cuerpo de un hombre de sesenta y ocho años que regresaba de un viaje de negocios a la Península Arábiga. El síndrome respiratorio del Medio Oriente (MERS) fue reconocido como una enfermedad tres años antes y apodado "gripe de camello", porque parece que los dromedarios transmiten el virus y lo transmiten a los humanos. El virus MERS puede haber provenido originalmente de murciélagos, quizá del murciélago de las tumbas egipcias, pero que probablemente ha circulado en los camellos durante al menos treinta años. Es posible que se haya extendido a los humanos antes de 2012, pero, de ser así, esas infecciones pasaron desapercibidas. Nadie sabe si un camello estornudó sobre el empresario surcoreano durante sus paradas en Bahréin, Qatar, Arabia Saudita y Emiratos Árabes Unidos, o si contrajo la infección de otra persona, pero esa pregunta poco importaba a los 186 surcoreanos infectados por él, directa o indirectamente, y aún menos a los 38 que murieron.

Los episodios de súper propagación impulsaron este brote, pero fue exacerbado por varios aspectos del sistema de salud de Corea del Sur. Debido a que los ciudadanos reciben atención médica barata a través de un plan de seguro nacional, con pocas restricciones sobre el hospital al que acuden, las personas visitan varios antes de elegir. El empresario fue a tres hospitales después de sentirse enfermo, y finalmente fue admitido en un cuarto hospital, en Seúl, donde le 
diagnosticaron MERS. Para entonces había infectado a 29 personas, dos de las cuales se convirtieron en súper difusores, que contagiaron a otras 97. A veces había cuatro o más camas en una habitación de hospital, y los pacientes podían recibir visitas; esto contribuyó a la propagación, así como la mala ventilación, el deficiente control de la infección y los limitados criterios para la cuarentena, de modo que no se detectó a las personas que contrajeron la infección por contacto casual. "En ese momento entendieron lo que sucede cuando un coronavirus causa infecciones adquiridas en el centro de salud de una comunidad y que saltan de un hospital a otro", comentó Khan. En Corea del Sur, el MERS se convirtió en un ejemplo de libro de texto de los desaciertos que llevan a la "propagación nosocomial", el término que denota las infecciones adquiridas en centros de salud. Cuando llegó la COVID-19, Khan me dijo: "Supongo que aún era una herida abierta para ellos".

E1 SARS solo golpeó levemente a Estados Unidos: produjo 27 casos probables, sin muertes, probablemente por razones de suerte. E1 MERS fue aún menos notorio: dos casos en 2014, ambos en trabajadores de la salud que regresaron de periodos de servicio en Arabia Saudita, sin propagación secundaria. Aparte de los CDC, casi nadie más lo notó.

Hubo otras advertencias, de científicos. En una serie de artículos oscuros pero importantes publicados en los últimos quince años, la mayoría con la palabra "murciélago" en el título, y muchos con el nombre de Zheng-Li Shi en la lista de autores, los investigadores aclararon las conexiones entre coronavirus, murciélagos y humanos.

Zheng-Li Shi es una viróloga de cincuenta y cinco años, educada en Wuhan y en Francia, que dirige un laboratorio en el Instituto de Virología de Wuhan. En 2004 hizo su primera expedición para cazar murciélagos en cuevas chinas, y un año después codirigió el grupo de investigadores que demostró que el virus del SARS, descubierto por Peiris como causa del síndrome en humanos, era transmitido a los humanos por murciélagos. Antes de ese estudio, se seguía una pista falsa que apuntaba a la civeta enmascarada de la palma -un carnívoro salvaje que se parece a un tejón, apreciado en el comercio de carne de animales salvajes- y rápidamente se sacrificaron miles de civetas cautivas. Luego llegaron mejores datos del grupo de Shi. En 2013, fue coautora de un artículo que arrojó luz sobre cómo algunos coronavirus transmitidos por murciélagos - pero no otros-logran infectar a los humanos. Sus proteínas en forma de púas (las protuberancias 
que dan a cada partícula viral su aspecto de corona) se unen bien a los receptores, no solo en las células de murciélago sino también en algunas células del tracto respiratorio humano En una especie de gancho y pestillo; los pestillos, conocidos como receptores $\mathrm{ACE}-2$, permiten que el virus penetre en la célula. Una vez dentro, el genoma viral toma el control de partes del aparato celular para replicarse, y comienza la infección.

En esos días, Shi y su equipo empezaron a centrarse en una cueva de las afueras de Kunming, capital de la provincia de Yunnan, en una zona famosa por sus pintorescas formaciones kársticas. Tomando muestras de loa fluidos corporales de los murciélagos que usaban la cueva como refugio, los investigadores encontraron una gran diversidad de coronavirus., incluidos tres que tenían el equipo adecuado - proteínas con púas capaces de unirse a los receptores ACE-2 para infectar a los humanos. "Este trabajo", advirtieron en un artículo de 2017, "destaca la necesidad de prepararnos para la aparición futura de enfermedades similares al SARS”. Una de las cepas de coronavirus que encontraron, en un murciélago de herradura, luego se denominó RaTG13 (que no es un acrónimo sino un código de conveniencia). Vale la pena echar un vistazo a esa tosca denominación, porque RaTG13 es el pariente conocido más cercano de lo que hoy llamamos SARS-CoV-2, cuyos genomas tienen un grado de similitud del $96,2 \%$, que en el mundo de los coronavirus los convierte en primos hermanos.

Uno de los coautores de Shi en ese artículo fue su colaborador de mucho tiempo Peter Daszak, presidente de EcoHealth Alliance, una organización científica sin ánimo de lucro con sede en Nueva York dedicada a la conservación biológica y la prevención de pandemias. Daszak elogia a Shi por su infatigable diligencia científica, la solidez de su trabajo de laboratorio y mucho más. "He hecho trabajo de campo y cantado al karaoke con ella", me dijo. "Es la mejor cantante del Instituto de Virología de Wuhan".

Shi, Daszak y sus colegas no solo advirtieron al mundo, hace tres años, que podía aparecer una nueva enfermedad similar al SARS. Pusieron a inspección, como bajo una lupa, una variante cercana del virus que causaría la pandemia de COVID-19 (recientemente en el Washington Post se han hecho preguntas sobre la posibilidad de que un virus cultivado en el laboratorio de Shi escapara de la contención y sembrara el brote en Wuhan, pero hasta ahora no hay evidencia científica que lo demuestre y hay considerable evidencia en contra). Añadieron, además, que no era solo un virus del que debíamos tener 
cuidado, pues varios virus similares al del SARS capaces de unirse a los receptores ACE-2 “circulan entre los murciélagos de esta región”.

$\mathrm{E} 1$ nuevo virus se reveló gradualmente en humanos en diciembre pasado, en Wuhan, y en enero varios laboratorios chinos, entre ellos el de Shi, secuenciaron total o parcialmente los genomas de muestras de diferentes pacientes, incluidos cinco genomas completos. E1 23 de enero, Shi y sus colegas anunciaron que el virus encontrado en esos cinco pacientes era un 96,2 por ciento idéntico al coronavirus del que había advertido tres años antes. Para entonces, el virus había circulado en Wuhan durante al menos siete semanas, y se habían difundido tres conceptos erróneos de graves consecuencias, no solo por líderes políticos sino también por funcionarios de hospitales y de la versión china de los CDC: que el brote había comenzado en el mercado mayorista de mariscos de Huanan, que vendía mucho más que mariscos; que el virus no era peligroso; y que no se transmitía de una persona a otra. En el segundo y el tercer punto había desacuerdo entre los médicos que trataban pacientes, como Zhang Li, en el Hospital Jinyintan de Wuhan, quien declaró al Wall Street Journal a finales de febrero: "Estaba alerta porque era un nueva neumonía y porque ya había tratado el SARS".

La idea errónea de que el mercado fue el origen del brote es negada implícitamente por un artículo científico publicado a finales de enero por un grupo de médicos de Wuhan y Beijing, que describía las características clínicas de los primeros 41 pacientes. El artículo decía que 27 de ellos habían estado expuestos en el mercado de Huanan. Puesto que es improbable que un solo murciélago de herradura infecte a 27 personas, aunque se corte en trozos para preparar entremeses, y puesto que según algunos testimonios los murciélagos ni siquiera estaban a la venta en el mercado en ese momento, algunos científicos conjeturaban que existía un huésped animal intermedio -una serpiente, un pangolín, una civeta de la palma- en el que el virus se amplificaba, antes de vender o sacrificar a esa criatura más grande. La evidencia molecular de las serpientes es débil, los pangolines son una historia complicada y las civetas no están implicadas esta vez. Daniel R. Lucey, médico y académico estadounidense (que también enfrentó el brote de SARS en Cantón, Hong Kong y Toronto), se preguntó acerca de los otros 14 pacientes. Observó que el primero de ellos, que enfermó el 1 de diciembre, no tuvo contacto directo ni indirecto con el mercado. Dado el periodo de incubación, eso significaba que el virus debió circular fuera del mercado de Wuhan desde noviembre. Esto no contradice la probabilidad de que el virus se haya originado en un 
murciélago, pero sugiere que tal vez entró en el mercado de Huanan, y salió de allí, en humanos. El SARS-CoV-2 es un bicho sutil.

Con el vívido recuerdo del SARS en la memoria, Singapur reaccionó rápida y decisivamente a la COVID-19. Cerró las fronteras a los no residentes, usó los hospitales de aislamiento y las salas de presión negativa construidos desde 2003, hizo gran cantidad de pruebas, rastreó contactos y los envió a cuarentena doméstica, e integró el liderazgo político y sanitario para enviar mensajes claros, veraces y coherentes. A pesar de todo ello, el país no estuvo en confinamiento hasta comienzos de abril, cuando los números cambiaron abruptamente y golpeó una segunda ola.

Asimismo, Corea del Sur ha usado pruebas exhaustivas, aislamiento y cuarentenas para mantener una baja carga de trabajo. Aunque la capital, Seúl, está a menos de tres horas de Wuhan en avión, el país ha registrado menos casos y muertes que Suecia o Perú. Por supuesto, eso podría cambiar rápidamente.

"Corea del Sur es un buen ejemplo que debemos observar", me dijo Khan. Su primer caso se confirmó el 20 de enero, el mismo día en que se confirmó el primer caso en Estados Unidos. "Adoptaron un enfoque muy diferente, y todo lo que teníamos que hacer era observar lo que estaban haciendo y decir: 'Haremos lo mismo'. Pero no lo hicimos”. E1 10 de enero China difundió la primera secuencia genómica del virus tomada de un paciente humano. Después de confirmar su primer caso, los funcionarios surcoreanos pronto se reunieron con las compañías de suministros médicos y las instaron a desarrollar kits de prueba y comenzar la producción en masa. Poco después, los científicos de Estados Unidos secuenciaron sus propias muestras, pero pasó el tiempo sin que se tomaran medidas significativas. "Todos los días posteriores al 22 de enero fueron días perdidos... por el gobierno de Estados Unidos", me dijo Khan. Podríamos haber recurrido a Becton Dickinson (una empresa gigante de tecnología médica) y decir a sus directivos que necesitábamos los medios para hacer pruebas en todo el país para el lunes siguiente, dijo. No lo hicimos ¿Por qué? Por falta de imaginación. Los científicos podían describir los riesgos, los funcionarios de salud podían diseñar una respuesta, pero los burócratas de las agencias del gobierno y los líderes nacionales no entendieron qué tan grave podía ser el brote. E1 30 de marzo, Donald Trump dijo: "Nadie tenía ni idea".

El primer caso reportado en Estados Unidos fue el de un hombre de 35 años que fue a visitar a sus parientes en Wuhan y regresó al área 
metropolitana de Seattle el 15 de enero (últimamente se reportaron otros dos casos iniciales en el condado de Santa Clara, California, que sugieren que el virus pudo estar presente en Estados Unidos antes del 15 de enero; ambos pacientes fallecieron en febrero, pero solo a fines de abril la autopsia reveló que eran positivos a la COVID-19). E1 hombre del área de Seattle llegó el 19 de enero a una clínica de urgencias, quejándose de fiebre y tos persistente. La tos es la forma más evidente de dispersión del SARS-CoV-2 a otros huéspedes; así, durante al menos cuatro días, ese hombre pudo haber transmitido la infección a otros habitantes del condado de Snohomish, contiguo a Seattle, y quizá a los pasajeros del avión (si ya portaba el virus, aunque fuese asintomático). En la clínica, sus viajes causaron preocupación, y uno de quienes lo atendieron lo notificó al personal del Departamento de Salud del Estado, que lo transmitió al Centro de Operaciones de Emergencia de los CDC. Tomen muestras y las examinaremos, respondieron allí. Al hombre se le hicieron muestra de sangre y con un hisopo, y volvió a su casa. Al día siguiente, cuando la prueba resultó positiva, ingresó al hospital, en una sala de aislamiento.

La respuesta desastrosamente tardía, inadecuada, confusa y (para muchos ciudadanos) desorientadora del gobierno federal a la COVID-19, tanto antes como después del primer caso, se deriva de demasiados factores para enumerarlos aquí, pero mencionaré dos: la falla para entender las advertencias del SARS y el MERS, ambas enviadas por otros coronavirus; y la pérdida de capacidad en los altos niveles del gobierno, en los últimos años, para entender la gravedad y la inmediatez de las amenazas de pandemia. El resultado de esta pérdida es lo que Ali Khan quiere decir cuando habla de falta de imaginación. Beth Cameron, ex directora de Seguridad Sanitaria Global y Biodefensa del Consejo de Seguridad Nacional, la llama ausencia de "la alarma de humo". Cameron me dijo que quienes están en el poder y están a cargo de "vigilar para adelantarse a las emergencias", necesitan percibir el olor del humo y apagar el fuego mientras es pequeño. "No vas a evitar que ocurran brotes. Pero puedes evitar que se conviertan en epidemias o pandemias". Cameron dirigió el organismo desde su fundación, después de la epidemia de ébola de 2014 en África occidental, hasta marzo de 2017. Este sobrevivió bajo su sucesor durante poco más de un año, y luego, después de que John Bolton se convirtió en asesor de seguridad nacional, fue disuelto. Una alarma de humo no funciona cuando se retira la batería.

Dennis Carroll, antiguo investigador en virología, dirigió una unidad de amenazas de pandemia de la Agencia de Estados Unidos 
para el Desarrollo Internacional durante al menos quince años. En 2009, estableció un gran programa llamado PREDICT, que distribuyó unos 200 millones de dólares en subvenciones para financiar el descubrimiento de nuevos virus potencialmente peligrosos antes de que se desborden a los humanos. Ese programa está llegando a su fin debido a la "ascensión de burócratas aversos al riesgo", le dijo al Times en octubre pasado. Mencionó la decisión de la Casa Blanca de cerrar la Dirección de Seguridad Sanitaria del Consejo de Seguridad Nacional como una ilustración paralela, y dijo que tanto el Congreso como las administraciones de George W. Bush y de Barack Obama habían dado "gran apoyo", pero luego llegaron los vientos fríos actuales.

Estados Unidos no está solo. "La comunidad global vive momentos difíciles para invertir en lo que se puede considerar riesgo”, me dijo Carroll hace poco. Gastar mucho dinero es en sí mismo una forma de riesgo, en especial si es dinero público, incluso si se gasta para protegerse contra un riesgo mayor. ¿Qué sucede si se gastan mil o diez mil millones de dólares (una pequeñez en comparación con lo que está costando la COVID-19), y no hay una pandemia durante el ejercicio del cargo? "La motivación para esa inversión es muy pequeña cuando la amenaza no es clara y no está presente”, comentó Carroll. Cuando aparece el SARS, cuando estallan una pandemia de gripe porcina o una epidemia de ébola, los líderes políticos y los donantes privados reaccionan con preocupada generosidad, pero cuando termina la crisis - dijo- "vemos un colapso total de ese tipo de inversión". Los propietarios de vivienda contratan seguros contra incendios, los gobiernos compran grandes arsenales de armamento con la esperanza de que no se usen, pero son reacios a invertir seriamente en prepararse contra pandemias. "Es un trastorno de déficit de atención a escala global”, sentenció Carroll.

Al final de The Next Pandemic, Ali Khan propuso otra metáfora: "Ha llegado el momento de dejar de ver la salud pública como un martillo de uso excepcional, cuya inscripción dice: EN CASO DE EMERGENCIA ROMPA EL VIDRIO”. Necesitamos invertir en medidas de prevención -escribió- para que nuestras comunidades sean resistentes a esa pesadilla, y eso significa: investigación de campo para descubrir nuevos virus; monitoreo vigilante de los desbordamientos; sistemas para producir pruebas de diagnóstico rápidamente y en grandes cantidades; mayor capacidad de respuesta de los prestadores de servicios sanitarios; cadenas corta y eficaces de ágil suministro de equipos de protección personal y de ventiladores, y programas 
coordinados para trasladarlos de una jurisdicción a otra; planeación coordinada entre ciudades, estados, provincias, naciones y agencias internacionales para contener desastres infecciosos; educación pública para fortalecer la disposición general a soportar el distanciamiento social y el monitoreo de las cuarentenas; mejor liderazgo en la salud pública y ciclos de financiación confiables; y lo más crítico, la voluntad política de arriesgarse a pagar por una preparación que podría no ser prontamente utilizada.

Quizá podamos contar con todo eso cuando ocurra la próxima pandemia, pero es demasiado tarde para prepararnos contra esta. "Es usual que mi papel sea responder a tales brotes en el extranjero", me dijo Khan la última vez que hablamos por Skype. Esas misiones marcaron la totalidad de su carrera en los CDC y en la siguiente. Pero esta vez no ha viajado. "Hay trabajo más que suficiente aquí en Estados Unidos", me dijo. Puede pasar parte del día tomando decisiones sobre los cursos de otoño y la escasez de presupuesto en la Facultad de Salud Pública, convocando reuniones en línea, consultando a funcionarios locales o estatales sobre medidas de salud pública, o a empresas privadas para mantener la seguridad de sus empleados y sus clientes. Cuando 157 estadounidenses que fueron evacuados de Wuhan aterrizaron en el aeropuerto de Omaha, a principios de febrero, Khan ayudó a organizar su cuarentena en Camp Ashland, una base de la Guardia Nacional a lo largo del río Platte. Da entrevistas a los medios de comunicación, supervisa el despliegue de grupos de estudiantes para rastrear contactos en Nebraska e Iowa, actúa como consultor de plantas procesadoras de carne y participa en el comité directivo de Global Outbreak Alert and Response Network, una red de expertos que trabajan bajo la guía de la OMS para estudiar, anticipar y responder a brotes y emergencias sanitarias. Igual que muchos de nosotros, hoy pasa mucho tiempo en Skype, Zoom y en el teléfono, pero para él la esencia de las discusiones consiste en las pruebas clínicas de medicamentos, la respuesta inmune, lo último en modelación epidemiológica y la mejor manera de descontaminar mascarillas N95.

E1 número total de casos en Nebraska está aumentando: de un paciente confirmado, el 6 de marzo, a millares. Nebraska ocupa un bajo lugar en casos y muertes, pero también en pruebas, por lo que se desconoce el número real de personas infectadas en el estado. El gobernador Pete Ricketts cerró las escuelas, prohibió las reuniones de más de diez personas en algunos condados y declaró el estado de emergencia, pero se negó a emitir la orden de quedarse en casa. Oma- 
ha es la sede del condado de Douglas, el más densamente poblado del estado y con el aeropuerto de mayor tráfico; y tiene un número significativo de casos. Así, mientras Ali Khan está sentado en su oficina, entre fotos y recuerdos de una vida en la primera fila de lucha contra enfermedades infecciosas, la pandemia está llegando hasta él. 